\title{
Degradation, Characterization, Ferrous Ion Chelating Ability and Repair Effect of Sulfated Polysaccharides of Six Kinds of Seaweed Polysaccharides
}

\author{
Xin-yuan SUN, Da GUO, Jian-min WANG and Jian-ming \\ OUYANG ${ }^{a, *}$ \\ Department of Chemistry, Jinan University, Guangzhou 510632, China \\ atoyjm@jnu.edu.cn \\ ${ }^{*}$ Corresponding author
}

Keywords: Antioxidant, Cell repair, Sulfated polysaccharides

\begin{abstract}
Six kinds of seaweed polysaccharides (SPSs) extracted from Laminaria japonica, Porphyra yezoensis, Gracilaria lemaneiformis, Sargassum fusiforme, Eucheuma gelatinae and Undaria pinnatifida were degraded and characterized. The sulfate group $\left(-\mathrm{OSO}_{3} \mathrm{H}\right)$ content of these polysaccharides were 21.7, 17.9, 13.3, 8.2, 7.0, and $5.5 \%$, respectively. The ferrous ion chelating ability and repair effect on injured human kidney proximal tubular epithelial cells (HK-2) of these polysaccharides were studied. These polysaccharides had stronger ferrous ion chelating ability, suggesting that it possessed high antioxidant activity. Each polysaccharide had a repair effect on oxalate-induced damaged HK-2 cells. The antioxidant activity and repair ability of polysaccharide was positively correlated with its $-\mathrm{OSO}_{3} \mathrm{H}$ content. These results indicated that these polysaccharides, especially those with high $-\mathrm{OSO}_{3} \mathrm{H}$ content, may be potential drugs for the prevention and treatment of calcium oxalate stones.
\end{abstract}

\section{Introduction}

Renal stone disease has afflicted humans for centuries. Kidney stones affect up to 5\% of the population, with a lifetime risk of passing a kidney stone of about 8-10\% [1]. Crystallization alone is not enough to explain the formation of renal stones. Cellular events include adherence of crystal to epithelial cell, cell injury and crystal edocytosis, occured in cells of the renal epithelium and interstitium. The interaction of calcium oxalate $(\mathrm{CaOx})$ crystals to renal epithelial cells is a key step towards the occurrence of stones, which changes cell functions and extracellular environment. Both in vivo and in vitro studies have suggested that $\mathrm{CaOx}$ crystals are injurious to renal epithelial cells, and induced renal tubular cell injury which resulted in the crystal attachment.

Oxalate is one of the major constituents of renal stone which is thought to produce free radicals thereby damaging the renal tubular cells. Injured epithelial cells might act as nidi for stone formation by aggravating $\mathrm{CaOx}$ precipitation during hyperoxaluria.

The molecular structure of the seaweed polysaccharide (SPSs) is composed of repeating disaccharide sugar chain, similar to GAGs. Therefore, seaweed polysaccharides may used to repair the damaged renal tubular epithelial cells, thereby preventing and inhibiting the formation of stones. For example, Laminaria polysaccharide and Sargassum polysaccharides had significant protection and repair effect on the kidney.

The biochemical activities of seaweed polysaccharides were closely related to total sugar content, sulfate content and molecular weight of polysaccharides [2], the activities of degraded polysaccharide with low molecular weight were often better than 
original high molecular weight polysaccharide [3]; when the molecular weight and molecular structure of polysaccharides were similar, the higher content of sulfate the polysaccharides contain, the stronger the biochemical activities were [4].

In this paper, we wanted to compare the antioxidant activities and repair ability on renal epithelial cells of seaweed polysaccharide with similar molecular weight but different $-\mathrm{OSO}_{3} \mathrm{H}$ contents, thereby studing the effects of $-\mathrm{OSO}_{3} \mathrm{H}$ content of polysaccharide on biochemical activities.

\section{Experimental Methods}

\section{Reagents and Apparatus}

Six kinds of seaweed polysaccharides extracted from Laminaria japonica, Porphyra yezoensis polysaccharide, Gracilaria lemaneiformis, Sargassum fusiforme, Eucheuma gelatinae and degraded Undaria pinnatifida were produced by Beijing Newprobe Bioscience \& Technology Co., Ltd.

\section{Degradation of Polysaccharides}

Polysaccharides were introduced into reactor containing liquor at desired $\mathrm{pH}$ and hydrogen peroxide concentration at $90^{\circ} \mathrm{C}$. The degradation reaction was allowed to proceed for $2 \mathrm{~h}$. After degradation, the molecular weight of each polysaccharide was controlled to about 10000 Da.

\section{Analysis of Sulfate Group Content}

The sulfate content of seaweed polysaccharide was determined by $\mathrm{BaCl}_{2}$-gelatin turbidity method. The obtained regression equation was shown in Fig. 1.

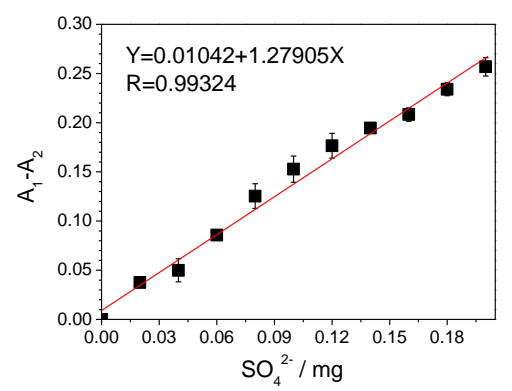

Fig. 1. Standard curve for determination of sulfate group content in seaweed polysaccharides by $\mathrm{BaCl}_{2}$-gelatin method.

\section{Ferrous Ion Chelating Ability of SPSs}

$1.0 \mathrm{~mL}$ polysaccharide solution in different concentrations were mixed with ferrous chloride $(0.05 \mathrm{~mL}, 2.0 \mathrm{mmol} / \mathrm{L}), 0.2 \mathrm{~mL}$ ferrozine $(5.0 \mathrm{mmol} / \mathrm{L})$ and $2.25 \mathrm{~mL}$ distilled water. After mixing for 10 min, ferrozine can form stable complexes with $\mathrm{Fe}^{2+}$ ions, which has characteristic absorption at $562 \mathrm{~nm}$ and can be detected by UV-Vis spectrophotometer. When the polysaccharide solution was added, $\mathrm{Fe}^{2+}$ content was decreased due to the chelation of polysaccharide and $\mathrm{Fe}^{2+}$, and the absorbance was reduced. In the blank group, polysaccharide solution was substituted with distilled water. In the control group, ferrous chloride solution was substituted with distilled water. EDTA was used as positive control. The ion-chelating activity of polysaccharides was calculated as:

$$
\mathrm{I} / \%=\left[\mathrm{A}_{0}-\left(\mathrm{A}_{1}-\mathrm{A}_{2}\right)\right] / \mathrm{A}_{0} \times 100
$$


Where I was scavenging rate $1 \% ; \mathrm{A}_{1}$ was the absorbance in the presence of the sample; $A_{2}$ was the absorbance of control group; $A_{0}$ was the absorbance of blank group.

\section{Repair Effect of SPS on Damaged HK-2 cells}

One hundred microliters of cell suspension with a cell concentration of $1 \times 10^{5}$ cells $/ \mathrm{mL}$ was inoculated per well in 96-well plates and incubated in a $5 \% \mathrm{CO}_{2}$ humidified atmosphere at $37{ }^{\circ} \mathrm{C}$ for $24 \mathrm{~h}$. Afterward, the medium was changed to serum-free DMEM culture medium and then incubated for another $12 \mathrm{~h}$ to achieve synchronization. The cells were then divided into three groups: 1) Control group, in which only serum-free culture medium was added; 2) Injury group: the serum-free medium containing $2.8 \mathrm{mmol} / \mathrm{L}$ oxalic acid $\left(\mathrm{H}_{2} \mathrm{Ox}\right)$ was added and incubated for $\left.3 \mathrm{~h} ; 3\right)$ Repair group: each evaluated polysaccharide with the concentration of $20,40,60,80$, and 100 $\mu \mathrm{g} / \mathrm{mL}$ was added to injury group cells and repaired the cells for $8 \mathrm{~h}$. After the repair was completed, the OD value of each group was detected at $450 \mathrm{~nm}$ according to CCK-8 kit test method, and detected the viability of cells.

\section{Results and Discussion}

\section{Characterization of Polysaccharides with Different Sulfate Group (-OSO Content by FT-IR Spectroscopy}

Fig. 2 demonstrated the FT-IR spectra of six seaweed polysaccharides (SPS). The peak at about $1253 \mathrm{~cm}^{-1}$ was due to stretching vibration of $\mathrm{S}=\mathrm{O}$. The peak at about $1620 \mathrm{~cm}^{-1}$ was attributed to the asymmetric and symmetric stretching vibrations of $\mathrm{COOH}$. The peak at about $933 \mathrm{~cm}^{-1}$ was attributed to the stretching vibration of $\mathrm{C}=\mathrm{O}$ in uronic acid. The peak at about $1382 \mathrm{~cm}^{-1}$ could be assigned to deforming vibrations of $\mathrm{C}-\mathrm{H}$ bond. The peak of $881 \mathrm{~cm}^{-1}$ could be assigned to $\mathrm{C}$-H scissor vibration of $\beta$-type heterogeneous glycosidic bond. A wide peak at about $3420 \mathrm{~cm}^{-1}$ was due to the hydroxyl stretching vibration and the peak at about $2925 \mathrm{~cm}^{-1}$ was due to $\mathrm{C}-\mathrm{H}$ stretching vibration.
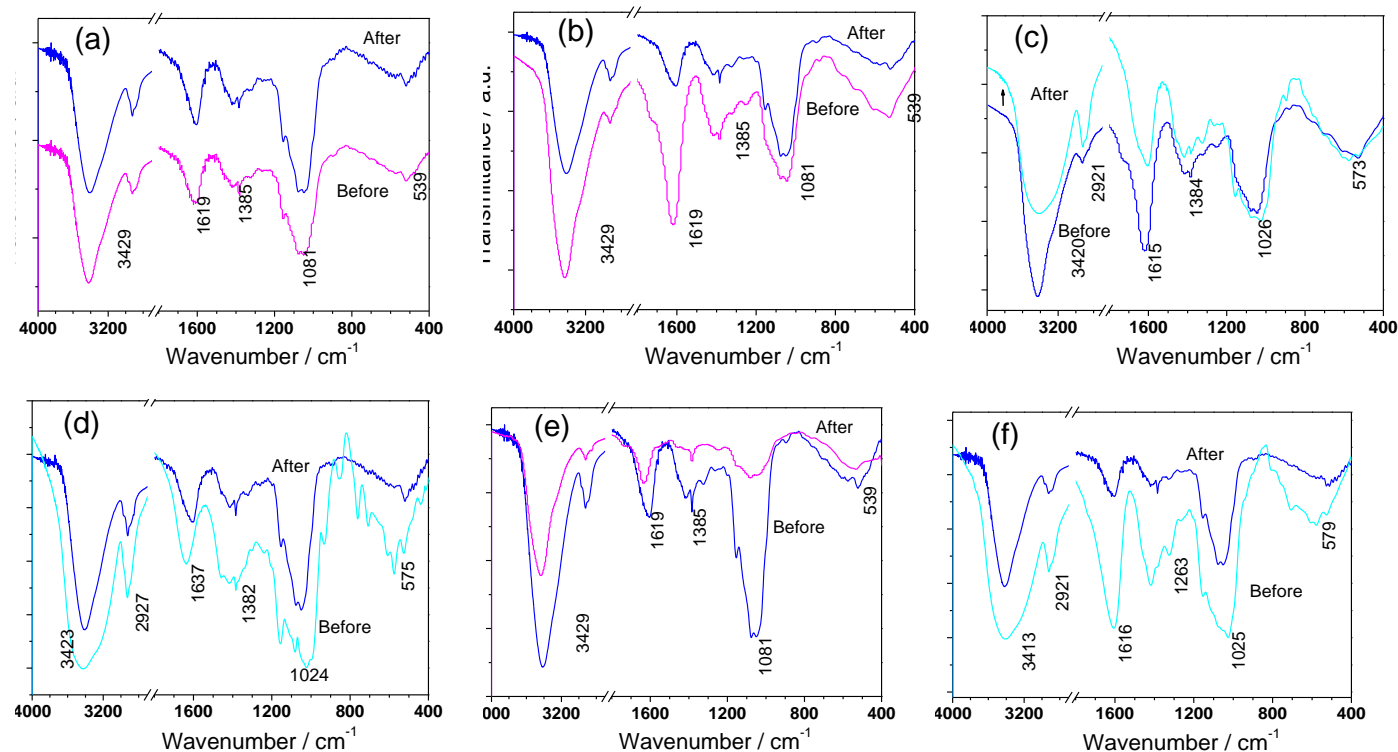

Fig. 2. FT-IR spectra of six seaweed polysaccharides before and after degradation. (a) Laminaria-1; (b) Porphyra-2; (c) Gracilaria-3; (d) Sargassum-4; (e) Eucheuma-5; and (f) Undaria-6. 
The FT-IR spectrum of the degraded polysaccharides was close to the undegraded samples, which indicated that the overall structure of polysaccharides did not cause a large impact by the hydrogen peroxide degradation.

Results of the FT-IR spectra suggested that there was a positive correlation between absorption peak intensity of $-\mathrm{OSO}_{3} \mathrm{H}$ (at about $1253 \mathrm{~cm}^{-1}$ ) and $-\mathrm{OSO}_{3} \mathrm{H}$ contents of polysaccharide. For instance, the FT-IR absorption peak intensity of $-\mathrm{OSO}_{3} \mathrm{H}$ of Laminarin- 1 was strongest and its $-\mathrm{OSO}_{3} \mathrm{H}$ content was the highest $(21.7 \%)$. The FT-IR peak intensities of - $\mathrm{OSO}_{3} \mathrm{H}$ of Eucheuma- 5 and Undaria- 6 were weaker than other polysaccharides and corresponding $-\mathrm{OSO}_{3} \mathrm{H}$ contents were the lowest $(7.0 \%$ and $6.1 \%$, respectively). Using FT-IR, peak intensity of $-\mathrm{OSO}_{3} \mathrm{H}$ was drawn as $\mathrm{Y}$-axis and - $\mathrm{OSO}_{3} \mathrm{H}$ content as $\mathrm{X}$-axis, it can be seen that there was existed approximate linear relationship between peak intensity of $-\mathrm{OSO}_{3} \mathrm{H}$ and $-\mathrm{OSO}_{3} \mathrm{H}$ content (Fig. 3).

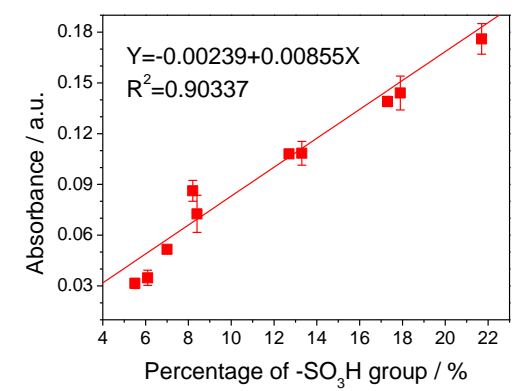

Fig. 3. Relationship between the content of $-\mathrm{OSO}_{3} \mathrm{H}$ in seaweed polysaccharides and the intensity of $-\mathrm{OSO}_{3} \mathrm{H}$ absorption peak in FT-IR.

\section{Chelating Effect of Spss on Ferrous Ions}

Metal chelating ability might be involved in antioxidant activity and affects other functions that contribute to the antioxidant activity. Ferrous ions $\left(\mathrm{Fe}^{2+}\right)$ are the most effective prooxidants in the food system, $\mathrm{Fe}^{2+}$ can stimulate lipid peroxidation and accelerate the oxidation of lipid compounds through the Fenton reaction. Therefore, the chelating effect of polysaccharides on ferrous ions might affect the other activities of scavenging free radicals to protect organisms against oxidative damages [5, 6].

As shown in Fig. 4, all four SPSs showed $\mathrm{Fe}^{2+}$ chelating capacity in a concentration-dependent manner. The chelating ability of ferrous ions strengthened with increasing $-\mathrm{OSO}_{3} \mathrm{H}$ content in seaweed polysaccharides at the same concentration.

Seaweed polysaccharides exhibited antioxidant activities in a concentration-dependent manner. Also the antioxidant ability of polysaccharide enhanced with the $-\mathrm{OSO}_{3} \mathrm{H}$ content of seaweed polysaccharides increased. That is, higher sulfate group content of polysaccharide indicated stronger antioxidant activity. The Porphyra-2 with highest sulfate group content $(17.9 \%)$ has strongest $\mathrm{Fe}^{2+}$ chelating capacity.

At the concentration of $2.0 \mathrm{mg} / \mathrm{mL}$, the $\mathrm{Fe}^{2+}$ chelating rate of polysaccharides decreased in the order of Porphyra-2 (92.3\%) > Gracilaria-3 (84.7\%) > Sargassum-4 $(76.3 \%)>$ Undaria-6 $(70.5 \%)$, which was consistent with the content order of sulfate group in polysaccharides $(17.9 \%, 13.3 \%, 8.2 \%$ and $5.5 \%$, respectively). 


\section{Repair Effect of Six Low Molecular Polysaccharides with Different Contents of - $\mathrm{OSO}_{3} \mathrm{H}$ Group on HK-2 Cells}

Fig. 5 shows that all polysaccharides considerably repaired damaged cells compared with the damaged control group. Simultaneously, when damaged cells were repaired by different concentrations of polysaccharides, the cell viability of damaged cells was initially increased, reaching the maximum at $60 \mu \mathrm{g} / \mathrm{mL}$, and then decreasing at higher concentrations ( 80 and $100 \mu \mathrm{g} / \mathrm{mL}$ ), indicating that $60 \mu \mathrm{g} / \mathrm{mL}$ was adequate for the polysaccharides to exert its biological activity.

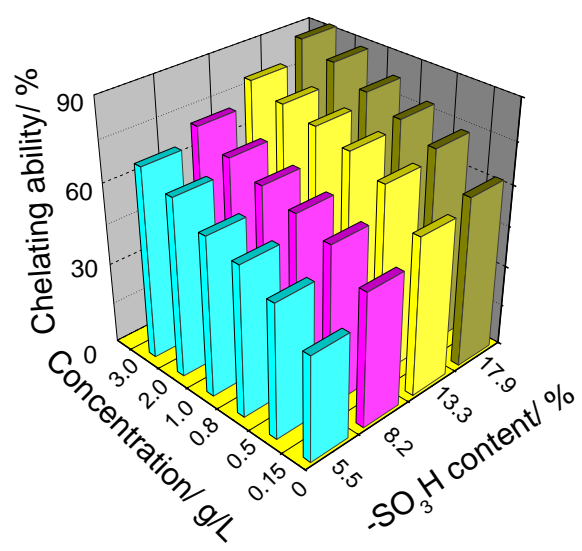

Fig. 4. Relationship between ferrous ions chelating ability and concentrations of SPSs with different $-\mathrm{OSO}_{3} \mathrm{H}$ content.
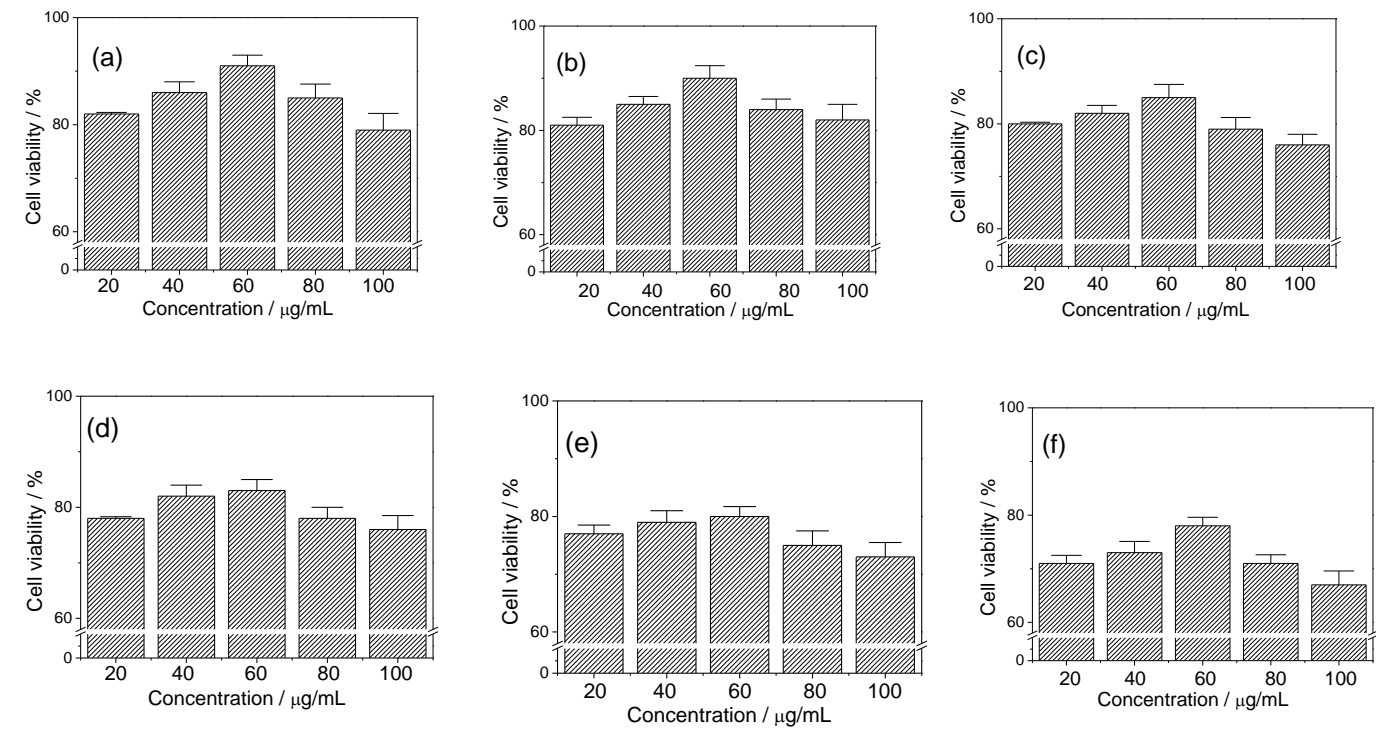

Fig. 5. Effect of different polysaccharide concentrations on the viability of oxalate-induced damaged HK-2 cells. (a) Laminaria-1; (b) degraded Porphyra-2; (c) degraded Gracilaria-3; (d) degraded Sargassum-4; (e) Eucheuma-5; (f) degraded Undaria-6. Cell viability was determined by CCK-8 assay.

That is, the repair ability of polysaccharide enhanced with the $-\mathrm{OSO}_{3} \mathrm{H}$ content of seaweed polysaccharides increased. The presence of $-\mathrm{OSO}_{3} \mathrm{H}$ groups in the SPS molecule can activate hydrogen atom of anomeric carbon, and make the group have higher activation ability and stronger hydrogen donating ability. That is, the supply of hydrogen by SPS can combine with radicals and form a stable radical to terminate the radical chain reaction [7]. 
It can be seen from Fig. 5 that SPSs promoted the proliferation of cells. The SPSs provided nutrition to cells, as cells divided rapidly due to sufficient nutrition and space. Similarly, Liang et al. [8] revealed that red seaweed SPSs (1-carrageenan) exerted no cytotoxicity and promoted the proliferation of human umbilical vein endothelial cells (HUVEC) within $5-1000 \mu \mathrm{g} / \mathrm{mL}$, and the cell viability was more than $140 \%$ at the concentration of $800 \mu \mathrm{g} / \mathrm{mL}$. Dore et al. [9] also found that the Sargassum vulgare polysaccharide increased viability of normal rabbit aortic endothelial cells to above $100 \%$ in the concentration range of $25-100 \mu \mathrm{g} / \mathrm{mL}$ and also promoted cell growth. Yao et al. [10] reported that Aloe polysaccharide (API) speeded up the proliferation of fibroblasts significantly, which OD value detected by MTT was 0.48, 0.51, 0.55, 0.59, 0.63 and 0.65 at the concentration of $0,25,50,100,200$ and $400 \mu \mathrm{g} / \mathrm{mL}$.

\section{Conclusions}

The seaweed polysaccharides with high molecular weight were degraded by hydrogen peroxide; degraded polysaccharides with similar molecular weights (about $10000 \mathrm{Da}$ ) but different $-\mathrm{OSO}_{3} \mathrm{H}$ contents $(21.7,17.9,13.3,8.2,7.0$ and $5.5 \%$, respectively) were obtained. The antioxidant ability and repair ability of polysaccharides were positively associated with the $-\mathrm{OSO}_{3} \mathrm{H}$ contents of polysaccharides. These polysaccharides had the best repair effect when the concentration was up to $60 \mu \mathrm{g} / \mathrm{mL}$.

\section{Acknowledgements}

This research work was granted by the Natural Science Foundation of China (No. 81670644, 21701050).

\section{References}

[1] L. Kovacevic, H. Lu, J. A. Caruso, Y. Lakshmanan, Renal tubular dysfunction in pediatric urolithiasis: proteomic evidence, Urology 92 (2016) 100-105.

[2] S. Narula, S. Tandon, S. K. Singh, C. Tandon, Kidney stone matrix proteins ameliorate calcium oxalate monohydrate induced apoptotic injury to renal epithelial cells, Life Sci. 164(2016) 23-30.

[3] H. Tsuji, W. Wang, J. Sunnil, N. Shimizu, K. Yoshimura, H. Uemura, A. B. Peck, S. R. Khan, Involvement of rennin-angiotensin-aldosterone system in calcium oxalate crystal induced activation of NADPH oxidase and renal cell injury, World J. Urol. 34(2016) 89-95.

[4] X. Zhao, C.-H. Xue, B.-F. Li, Study of antioxidant activities of sulfated polysaccharides from Laminaria japonica, J. Appl. Phycol. 20 (2008) 431-436.

[5] J. Peng, Y. Lei, D. Cai, L. Jiao, L. Zhang, Characterization and antioxidant activities of the polysaccharides from mycelium of Phellinus pini, and culture medium, Carbohyd. Polym. 117 (2015) 600-604.

[6] J. A. Benedet, T. Shibamoto, Role of transition metals, $\mathrm{Fe}(\mathrm{II}), \mathrm{Cr}(\mathrm{II}), \mathrm{Pb}(\mathrm{II})$, and Cd(II) in lipid peroxidation, Food Chem. 107 (2008)165-168.

[7] J. L. Wang, H. Y. Guo, J. Zhang, X. F. Wang, B. T. Zhao, J. Yao, Y. P. Wang, Sulfated modification, characterization and structure antioxidant relationships of Artemisia sphaerocephala polysaccharides, Carbohyd. Polym. 81 (2010) 897-905. 
[8] W. Liang, X. Mao, X. Peng, S. Tang, Effects of sulfate group in red seaweed polysaccharides on anticoagulant activity and cytotoxicity, Carbohydr. Polym. 101 (2014) 776-785.

[9] C. M. P. G. Dore, M. G. C. F. Alves, N. D. Santos, A. K. M. Cruz, R. B. G. Câmara, A. J. G. Castro, L. G. Alves, H. B. Nader, E. L. Leite. Antiangiogenic activity and direct antitumor effect from a sulfated polysaccharide isolated from seaweed. Microvasc. Res. 88 (2013) 12-18.

[10] H. Yao, Y. Chen, S. Li, L. Huang, W. Chen, X. Lin. Promotion proliferation effect of a polysaccharide from Aloe barbadensis Miller on human fibroblasts in vitro, Int. J. Biol. Macromol. 45 (2009) 152-156. 